\title{
PSYCHOHISTORY DALAM KAJIAN SELF-ESTEEM TEKS DEKLARASI NU 1983 TENTANG HUBUNGAN PANCASILA DAN ISLAM
}

\author{
Robit Nurul Jamil, ${ }^{1}$ Hermanu Joebagio, ${ }^{2}$ Djono ${ }^{3}$ \\ 123Pascasarjana Universitas Sebelas Maret, Surakarta - Indonesia \\ e-mail: 1robitnuruljamil93@gmail.com; 2hermanu.joebagio@staff.uns.ac.id; \\ 3djono_sk@yahoo.com
}

\begin{abstract}
Special concern on the sources of Islamic history contributes to the thoughts and identity of Indonesian Muslims. Muslim self-esteem can be formed from these historical sources. The formation of Muslim self-esteem gives the right decision so that it does not come out of the context of religion and humanity. The historical source used in this study is the text of the 1983 Nahdlatul Ulama Declaration (NU). The concept of Islam Nusantara (NU) 2015 is an implication of the values of the text of the declaration. The purpose of this study is to provide new insights regarding the 2015 NU's concept of Islam Nusantara by analyzing the historical sources of the text of the $1983 \mathrm{NU}$ Declaration and exploring the values of self-esteem contained in the text of the declaration. The study used a qualitative method with psychohistory approach. This study produced two discussions: 1) The 2015 NU's concept of Islam Nusantara. 2) Psychohistory self-esteem in the historical source of the text of the $1983 \mathrm{NU}$ Declaration. This study concluded that the conception of Islam Nusantara 2015 was mandated by the 1983 NU declaration, in its implementation provides Islamic self-esteem that can hinder the process of radicalization.
\end{abstract}

\begin{abstract}
Abstrak: Perhatian khusus terhadap sumber sejarah Islam memberikan sumbangan pemikiran dan jati diri Muslim Indonesia. Self-esteem Muslim dapat terbentuk dari warisan sumber sejarah tersebut. Terbentuknya self-esteem Muslim memberikan keputusan yang benar sehingga tidak keluar konteks agama dan kemanusiaan. Sumber sejarah yang digunakan dalam penelitian ini adalah teks Deklarasi Nahdlatul Ulama (NU) 1983. Konsep Islam Nusantara (NU) 2015 merupakan implementasi dari nilai-nilai teks deklarasi tersebut. Tujuan penelitian ini adalah memberikan pandangan baru terkait konsepsi Islam Nusantara NU 2015 dengan analisis sumber sejarah teks Deklarasi NU 1983 dan mengexplorasi nilai-nilai self-esteem yang terkandung di dalam teks deklarasi tersebut. Penelitian menggunakan metode kualitatif dengan pendekatan $p s y c h o-$ history. Penelitian ini menghasilkan dua bahasan: 1) Konsep Islam Nusantara NU 2015. 2) Psychohistory self-esteem dalam sumber sejarah teks Deklarasi NU 1983. Penelitian ini menyimpulkan bahwa konsepsi Islam Nusantara 2015 merupakan amanat deklarasi NU 1983, dalam implementasinya memberikan self-esteem Islam yang dapat menghalangi proses radikalisasi.
\end{abstract}

Keywords: Islam Nusantara; self-esteem; NU Declaration 1983 


\section{A. Pendahuluan}

Dinamika intelektual Islam di Indonesia telah mengalami degradasi pemahaman keislaman. Potensi disintegrasi terlihat jelas dengan kemunculan paham-paham ideologi alternatif. Paham ideologi alternatif dalam konteks ini memiliki sifat radikal, sehingga kerap disebut paham radikal dalam perkembangan intelektual Islam Indonesia. ${ }^{1}$ Kemunculan paham tersebut tidak diragukan lagi, konflik demi konflik menjelaskan tentang kemunculan paham radikal tersebut. Data yang disampaikan oleh beberapa tim survei memberikan argumentasi paham radikal tersebut sudah menjangkiti para intelektual. Alvara Research Center mendiagnosis radikalisme sudah menyebar di kalangan mahasiswa dan pelajar. Survei tersebut berkaitan dengan jihad dan khilafah atau negara Islam. Alvara Research Center bekerjasama dengan Mata Air Foundations melakukan survei kepada 1.800 Mahasiswa dan 2.400 pelajar. Lingkup survei mahasiswa dan pelajar di seluruh Pulau Jawa. Metode yang digunakan dalam survei adalah face to face interview. Mahasiswa setuju dengan paham negara Islam hampir $23.3 \%$ dan pelajar sekitar 16.3\%. Tentang konsep jihad dan khilafah sebayak $34.4 \%$ mahasiswa yang siap berjihad untuk tegaknya negara Islam dan untuk kalangan pelajar sebanyak $23.3 \%{ }^{2}$

Kemenristekdikti mengantisipasi gerakan tersebut dengan general education, progam yang berupa mata kuliah beserta kegiatan-kegiatan aplikatif yang berfungsi, menangkal paham radikalisme di perguruan tinggi dan sekolah menengah atas. Hal ini membuktikan bahwa paham ideologi alternatif radikalisme Islam sudah menyebar dan sangat memprihatinkan bagi kalangan intelektual Muslim. ${ }^{3}$ Di sisi lain konsepsi negara Islam bisa mengancam keutuhan ideologi negara. Sebab itulah dibutuhkan solusi dan penanganan khusus dalam penyatuan frame work keislaman Indonesia yang mendukung ideologi negara. ${ }^{4}$ Kemunculan konsepsi Islam Nusantara NU merupakan jawaban perihal

${ }^{1}$ Muhammad Akhyar Fadly, “Gerakan Radikalisme Agama: Perspektif Ilmu Sosial," El-Hikam: Journal of Education and Religious Studies 9, no. 1 (2016): 87-104, http://ejournal.kopertais4.or.id/ sasambo/index.php/elhikam/article/view/1881/.

${ }^{2}$ CNN, Survei Alvara_Sebagian Milenial Setuju Khilafah (2018).

${ }^{3}$ Anzar Abdullah, "Gerakan Radikalisme dalam Islam: Perspektif Historis," Addin 10, no. 1 (2016): 1-28, https://doi.org/10.21043/addin.v10i1.1127.

${ }^{4}$ Luqman Nurhisam dan Mualimul Huda, "Islam Nusantara: A Middle Way?," QIJIS: Qudus International Journal of Islamic Studies 4, no. 2 (2016): 152-66, https://doi.org/10.21043/ qijis.v4i2.1763. 
kondisi keislaman Indonesia, namun dalam pendoktrinan dan penyebaran paham terjadi dikotomi dan kesenjangan publik yang bermuara pada isu kontroversi, baik yang menerima konsepsi Islam Nusantara dan menolak konsepsi tersebut. $^{5}$

Secara intelektual posisi Islam Nusantara memberikan stigma positif dan negatif. Pada posisi positif Islam Nusantara mampu membendung paham radikalisme Islam yang sedang berlangsung di percaturan sosial intelektual masyarakat, sedangkan posisi negatif memberikan kerangka ilmiah mengenai konsep Islam Nusantara, Islam yang bersifat universal menjadi khas Nusantara, sehingga mengakibatkan penggolongan baru (spesifikasi) dalam Islam. ${ }^{6}$ Kondisi kontroversi ini banyak dimanfaatkan oleh pihak-pihak yang menginginkan lemahnya kaum Muslim di Nusantara maupun di dunia demi kepentingan politik dan ekonomi. Misalnya kebangkitan kaum Muslim di Timur Tengah memicu intervensi baru dalam gerakan-gerakan Islam. Analisis RAND Corporation pada tahun 2007 kebangkitan Muslim mengarah kepada kebebasan hegemoni Barat, sehingga RAND menilai orientasi ini akan membahayakan Barat, di sisi lain lembaga kajian yang didanai oleh pemerintah Amerika Serikat ini melaporkan adanya kesadaran masyarakat dunia untuk kembali kepada ajaran Islam. ${ }^{7}$

Melawan gerakan umat Muslim yang secara sadar ingin melepaskan diri dari hegemoni Barat tersebut RAND mengkawatirkan munculnya gerakan solidaritas jihad global kaum Muslimin jika mengambil langkah untuk memeranginya dan sekaligus membutuhkan dana yang besar. Maka dari itu untuk mengantisipasi risiko tersebut RAND mengambil langkah taktik. Salah satu taktik yang dipakai adalah politik adu domba yang memanfaatkan isu furu', isu "tradisional" dan transnasional, tujuannya yaitu membuat kaum Muslimin saling curiga, lemah ukhuwah dan kalah dalam siyasah. ${ }^{8}$ Pandangan kontemporer juga

\footnotetext{
${ }^{5}$ Abdul Moqsith Ghazali, "Metodologi Islam Nusantara," dalam Islam Nusantara: Dari Ushul Fiqh Hingga Paham Kebangsaan, ed. Akhmad Sahal dan Munawir Azis (Bandung: Mizan Pustaka, 2016), 106-16.

6Khoirurrijal, "Islam Nusantara sebagai Counter Hegemoni Melawan Radikalisme Agama," Akademika: Jurnal Pemikiran Islam 22, no. 1 (2017): 78-102, https://doi.org/10.32332/ akademika.v22i1.616.

${ }^{7}$ Angel Rabasa et al., Building Moderate Muslim Networks (Santa Monica, CA: RAND Corporation, 2007), https://www.rand.org/content/dam/rand/pubs/monographs/2007/RAND_ MG574.pdf.

${ }^{8}$ Rabasa et al.
} 
melihat posisi seperti ini dimanfaatkan kelompok Syiah dalam menebarkan jaringan politik dan hegemoni baru. Tidak bisa dipungkiri berkembangnya Syiah akan berbanding lurus dengan melemahnya Ahlus Sunnah. Refleksi sejarah mengatakan momentum ini pernah dimanfaatkan oleh dinasti Fathimiyah yang berkembang di wilayah Afrika Utara hingga wilayah Hijaz berkaitan dengan politik dan hegemoni di dalam kekhalifahan Abbasiyah. Kemunduran khilafah Abbasiyah pada waktu itu salah satu pemicunya adalah masalah internal di kalangan Ahlus Sunnah sendiri. Politik adu domba telah mendesain egoisme antar mazhab dan melemahkan kekhalifahan. Hal ini membuktikan proses pelemahan Islam dari dalam menjadi kekhawatiran khusus dalam kemunduran Ahlus Sunnah di era kontemporer sekarang, sehingga wajar muncul gerakangerakan revolusi Islam untuk menghindari masalah-masalah tersebut. Salah satunya adalah konvensi konsepsi Islam Nusantara NU 2015, konsepsi ini di sampaikan dalam Muktamar NU ke-33 di Jombang Jawa Timur. ${ }^{9}$

Konvensi Islam Nusantara memberikan pemahaman baru bukan dari aspek akidah melainkan asumsi normatif dan problematik sosial di dalam masyarakat Indonesia yang memiliki masyarakat beragam (plural). ${ }^{10}$ Nurcholish Madjid memberikan sebuah pandangan bahwa Indonesia merupakan salah satu bangsa paling pluralis di dunia. Memiliki 17.600 pulau baik besar maupun kecil, dihuni maupun tidak, Indonesia adalah negara kepulauan terbesar di dunia, dan negara yang memiliki keragaman sangat tinggi dalam hal suku, ras, bahasa, budaya, dan agama. ${ }^{11}$ Sebagaimana diakui oleh antropolog Robert W. Hefner ${ }^{12}$ keragaman budaya dan perbedaan adalah kenyataan yang tak bisa dipungkiri di Indonesia. Ada sekitar 656 kelompok etnis, besar dan kecil, hidup di wilayah Indonesia, memiliki budaya, tradisi, dan adat istiadat yang berbeda-beda menjadikan Indonesia sebagai negara dengan kebudayaan yang sangat beragam..$^{13}$ Kondisi masyarakat ini sangat rentan akan perpecahan atau

9 Panitia Muktamar PBNU, ed., Panduan Acara Muktamar ke-33 (Jombang: PBNU, 2015).

${ }^{10}$ Azyumardi Azra, “Kontestasi Pemikiran Islam Indonesia Kontemporer," Studia Islamika 23, no. 1 (2016): 175-84, https://doi.org/10.15408/sdi.v23i1.2905.

${ }^{11}$ Nor Huda, Islam Nusantara: Sejarah Sosial Intelektual Islam di Indonesia (Yogyakarta: ArRuzz Media, 2007).

${ }^{12}$ R. W. Hefner, The Politics of Multiculturalism: Pluralism and Citizenship in Malaysia, Singapore, and Indonesia (Hawai: University of Hawai'i Press, 2001).

${ }^{13}$ Azyumardi Azra, "Pluralism, Coexistence and Religious Harmony in Southeast Asia: Indonesian Experience in the 'Middle-path",'” dalam Contemporary Islam: Dynamic, not Static, ed. Abdul Aziz Said, Mohammed Abu-Nimer, dan Meena Sharify-Funk (London: Routledge, 2006), 22741. 
disintegrasi baru yang disebabkan politik adu domba maupun hal lainnya. Tujuan penulis mengkaji self-esteem dalam konsep Islam Nusantara NU adalah berusaha menghadirkan salah satu alternatif solusi nilai self-esteem, model pemikiran, pemahaman serta aksentuasi pengamalan ajaran-ajaran Islam yang humanis dan ramah, baik dalam lingkup geografis, sosial maupun budaya. Harapannya individu Muslim memiliki self-esteem sebagai warga negara, terlepas dari belenggu disintegrasi bangsa, dan perpecahan serta paham radikalisme yang menyebar. Ditinjau dari paparan di atas konflik Islam tidak lepas dari kaidah berbangsa dan bernegara, maka sajian penelitian ini menggunakan sumber sejarah deklarasi NU dalam konvensi ideologi negara (Pancasila) pada tahun 1983 yang mendasari self-esteem individu Muslim dan dasar konsepsi Islam Nusantara NU 2015.

Penelitian ini menggunakan paradigma kualitatif dengan pendekatan psychohistory. Psychohistory adalah studi tentang motivasi psikologis dari peristiwa bersejarah. Mencoba untuk menggabungkan wawasan psikoanalisis dengan metodologi penelitian ilmu sosial untuk memahami asal-usul emosional dari perilaku sosial dan politik kelompok dan bangsa, dulu dan sekarang. ${ }^{14}$ Cabang ilmu ini memang belum banyak dikenal oleh masyarakat luas, terutama di kalangan masyarakat Islam. Kekayaan dan warisan intelektual Islam menjadi terabai, padahal warisan intelektual yang berupa karya tulis itu begitu banyak. ${ }^{15}$ Dalam kajian self-esteem menggunakan pendekatan psychohistsory sangatlah tepat guna mencari motivasi kelompok yang di arahkan kepada individu Muslim. Analisis ini menggunakan sumber tertulis Nahdlatul Ulama' versi ArabIndo yaitu deklarasi hubungan Pancasila dan Islam tahun 1983 (terlampir).

\section{B. Kajian Historis Munas Nahdlatul Ulama' 1983 dan Konsep Islam Nusantara}

Perjuangan kemerdekaan bangsa Indonesia yang dicapai pada tahun 1945 dalam kajian historis memberikan sumbangsih literasi keterlibatan para ulama

14Peter Buckley, "The Psychohistory Review. VIII, 1979: A Note on the Adaptation of the Psychoanalytic Method to the Study of Historical Personalities: Psychoanalysts on Schreber. Carl Pletsch. pp. 46-50," The Psychoanalytic Quarterly 51 (1982): 169-70, https://www.pepweb.org/document.php?id=paq.051.0169c.

${ }^{15}$ Khabibi Muhammad Luthfi, "Kontekstualisasi Filologi dalam Teks-teks Islam Nusantara," Ibda: Jurnal Kajian Islam dan Budaya 14, no. 1 (2016): 114-28, https://doi.org/10.24090/ IBDA.V14I1.523. 
dalam kancah perpolitikan dan perjuangan bangsa. Banyak di kalangan ulama NU yang terlibat dalam perjuangan seperti K.H. Hasyim Asyari, K.H. Maskur, K.H. Wahab Hasbullah, K.H. Wahid Hasyim dan lain sebagainya. Hal itu dibuktikan dengan kepengurusan BPUK yang sebagian dari ulama. Mereka terlibat dalam perumusan UUD 1945 dan Pancasila sebagai ideologi bangsa. NU dengan konvensi negara tersebut menarik misi konsistensi dari 1945 hingga proses disintegrasi bangsa yang terjadi pada 1949-1950 yaitu menjadi garda terdepan pengawal ideologi Pancasila. Pasca demokrasi terpimpin kelahiran orde baru membawa kebutuhan Pancasila menjadi kebutuhan politik. Pancasila dijadikan sebagai sarana untuk mendiskriminasi dan menstigma kelompok lain. Kaum Nahdhiyin menyatakan setia pada Pancasila, oleh karena itu NU menolak segala penyimpangan penafsiran dan pengamalan Pancasila serta penerapan di luar batas seperti itu. 16

Keterlibatannya dalam menafsir ideologi Pancasila memberikan NU konsep ideologi yang sudah tuntas dalam hubungan negara. Hal itu membawa konsistensi tujuan sehingga membawa NU ke dalam gerakan untuk menolak penafsiran tunggal Pancasila yang dimonopoli Orde Baru melalui P4 dan sebagainya. ${ }^{17}$ Pancasila harus diletakkan sebagaimana fungsinya, social justice menjadi orientasi bersama dan kebutuhan Pancasila menjadi praktek bermasyarakat dan bernegara. Dalam perkembangannya Orde Baru menginstruksikan denggan desakan semua organisasi tidak hanya organisasi politik akan tetapi semua organisasi kemasyarakatan untuk menetapkan Pancasila sebagai satu-satunya asas. Dari sinilah timbul kecurigaan dalam penggunaan Pancasila sebagai dalih politik dan alat kesewenang-wenangan. Oleh sebab itu banyak penolakan atas kebijakan orde baru tersebut tidak hanya Islam tetapi juga agama yang lain. Melalui pembicaraan yang intensif antara K.H. As'ad Syamsul Arifin dan juga K.H. Ahmad Siddiq dengan Presiden Soeharto bahwa Pancasila tidak akan menggeser agama dan agama tidak akan di-Pancasila-kan, maka NU mau menerima Pancasila sebagai asas organisasi, tanpa harus meninggalkan Ahlussunnah wal-Jama'ah sebagai dasar akidahnya. ${ }^{18}$

\footnotetext{
${ }^{16}$ Anzar Abdullah, "Nahdatul Ulama and the Khittah Revitalization: A Futuristic Critical Reflection for the Largest Islamic Organization in Indonesia," Tawarikh: International Journal for Historical Studies 3, no. 1 (2011): 95-108, http://www.journals.mindamas.com/index.php/ tawarikh/article/view/398/.

${ }^{17}$ Nurlira Goncing, "Politik Nahdatul Ulama dan Orde Baru," The Politics: Jurnal Magister Ilmu Politik Universitas Hasanuddin 1, no. 1 (2015): 61-74.

${ }^{18}$ Goncing.
} 
Konsep tersebut diaktualisasikan dalam konsep penerimaan dalam satu tujuan, berbetuk piagam tertinggi dan awal mula dalam sebuah Deklarasi 1983 tentang hubungan Pancasila dengan Islam. Deklarasi penting itu dirumuskan pada tahun 1983 di Situbondo pada Konferensi Nasional Alim Ulama NU. Pernyataan NU menjadi kontroversial dan mengejutkan pada saat itu. Analisis tersebut menjadi kontroversi sebab tidak sedikit yang mengetahui misi politik dan kebangsaan organisasi $\mathrm{NU}$, yang mengerti akan argumen tersebut, akan mendapati analisis yang rasional, sistematis dan proporsional baik untuk individu mulim dan konsep kebangsaan. Tidak sedikit organisasi Islam lainnya yang berterima kasih kepada NU karena memecahkan masalah yang sangat rumit secara politik, terutama hubungan antara agama dan Pancasila. ${ }^{19}$ Dengan kecemerlangannya kembali ke khittah, NU mampu meletakkan hubungan yang proporsional antara agama dan Pancasila, sehingga NU bisa menerima Pancasila secara proporsional pula. Bahkan agama-agama lain merasa sangat berterima kasih pada NU sebab kemampuannya merumuskan hubungan Agama dengan Pancasila melalui argumen yang rasional dan mendasar baik secara syar'i maupun secara siyasi. Ketika undang-undang mengenai penerapan asas tunggal diberlakukan pada tahun 1985, maka jalan yang dirintis NU telah mulus, sehingga hampir semua ormas besar dan agama-agama resmi menerimanya. Hanya beberapa ormas Islam sempalan yang masih menentang Pancasila. Itulah jasa besar NU dalam menegakkan Pancasila sebagai falsafah dan dasar negara Republik Indonesia serta dasar bagi ormas yang ada. Pancasila sebagai filosofi dan fondasi Republik Indonesia dan menjadi dasar bagi organisasi sekarang ini, ${ }^{20}$ hal inilah yang kemudian menjembatani konsep publishing Islam Nusantara.

Islam Nusantara dalam pengertian khusus merupakan model Islam dalam pemahaman dan pemiikiran yang bersinergi ke dalam nilai-nilai kultural masyarakat Indonesia. Secara konsep perubahan sosial tersebut diakibatkan penafsiran kebudayaan yang disesuaikan dengan nilai keislaman sehingga menjadi pola baru dalam masyarakat. ${ }^{21}$ Sedangkan dalam metodologi dakwah Islam Nusantara sebagai pemahaman khusus dan penerapan universalitas

${ }^{19}$ Fokky Fuad, “Islam dan Ideologi Pancasila, Sebuah Dialektika," Lex Jurnalica (Journal of Law) 9, no. 3 (2012), https://ejurnal.esaunggul.ac.id/index.php/Lex/article/view/346.

${ }^{20}$ Ngainun Naim, "Islam dan Pancasila: Rekonstruksi Pemikiran Nurcholish Madjid," Epistemé: Jurnal Pengembangan Ilmu Keislaman 10, no. 2 (2015): 435-56, https://doi.org/10.21274/ epis.2015.10.2.435-456.

${ }^{21 E d i ~ S u s a n t o ~ d a n ~ K a r i m u l l a h ~ K a r i m u l l a h, ~ " I s l a m ~ N u s a n t a r a: ~ I s l a m ~ K h a s ~ d a n ~ A k o m o d a t i f ~}$ terhadap Budaya Lokal," Al-Ulum 16, no. 1 (2016): 56-80, https://doi.org/10.30603/au.v16i1.27. 
(shumuliyah) ajaran Islam yang sesuai dengan prinsip-prinsip Ahlussunnah walJama'ah. Ini merupakan aksentuasi baru dalam model yang telah mengalami cultural influence secara baik ('urf-șahịh) di Nusantara, sedangkan cultural influence yang tidak baik ('urf-fasid) dalam proses dakwah Islam Nusantara secara langsung mengalami amputasi, asimilasi, atau minimalisasi, tradisi lokal kemudian di sesuaikan dengan diktum-diktum syariah Islam agar tidak bertentangan secara akidah dan syariat. ${ }^{22}$

Demi mensterilkan kebudayaan Nusantara dari tradisi lokal yang menyesatkan, konsepsi Islam Nusantara mencoba hadir sebagai solusi alternatif cara ber-Islam yang sesuai dengan kaidah syariat Islam. Pada era kontemporer tahun terakhir konsep Islam Nusantara telah dijabarkan dan dikukuhkan ke dalam misi peneguhan pada tema utama Muktamar Nahdlatul Ulama' (NU) ke33 di Jombang 1-5 Agustus 2015. ${ }^{23}$ Peneguhan tema ini merupakan skema nasional NU untuk mempublikasikan Islam Nusantara lebih luas menembus masyarakat Muslim perkotaan hinnga pedesaan. Respon kondisi sosial-politik juga mempengaruhi pengangkatan tema tersebut, masyarakat Indonesia disuguhi masalah yang cenderung dinilai negatif, dampak dari kasus-kasus kekerasan yang dilakukan dengan mengatasnamakan Islam, baik pembunuhan, penyanderaan, pemboman dan sebagainya, ${ }^{24}$ sehingga mengakibatkan kondisi citra Islam di pentas nasional dan internasional semakin merosot, hal ini membuat kegaduhan sosial dan politik di kalangan masyarakat Islam Indonesia. Secara sosial masyarakat dihantui dengan Islamphobia disebabkan citra Islam yang negatif. Secara politik kegaduhan konsep khilafah telah mengancam keutuhan ideologi bangsa terbukti dengan adanya pembubaran ormas HTI yang dianggap keluar dari jalur ideologi bangsa. Kondisi ini mengancam posisi Islam dalam konteks berbangsa dan negara. Sintesa dari kondisi itu Islam Nusantara memposisikan diri sebagai respons solusi dalam masalah tersebut. ${ }^{25}$

Munculnya ide Islam Nusantara pada tahun 2015 dapat dilihat sebagai semacam aksi dan reaksi dinamis NU terhadap masalah internal dan eksternal

${ }^{22}$ Hanum Jazimah Puji Astuti, "Islam Nusantara: Sebuah Argumentasi Beragama dalam Bingkai Kultural," Inject: Interdisciplinary Journal of Communication 2, no. 1 (2017): 27-51, https://doi.org/10.18326/inject.v2i1.27-51.

23Panitia Muktamar PBNU, Panduan Acara Muktamar ke-33.

${ }^{24}$ Azyumardi Azra, "Islam in Southeast Asia: Tolerance and Radicalism," dalam Miegunyah Public Lecture (Melbourne: The University of Melbourne, 2005), 1-19.

${ }^{25}$ Luthfi, "Kontekstualisasi Filologi dalam Teks-teks Islam Nusantara." 
yang dihadapi organisasi. Sebagai tindakan, misalnya, Islam Nusantara adalah strategi $\mathrm{NU}$ dalam memperkuat ikatan anggota $\mathrm{NU}$ dengan organisasi mereka, di satu sisi, dan dengan tradisi lokal, di sisi lain. NU mengikuti pemikiran Ash'arī dan Māturidī (pendiri teologi Sunni dalam Islam), empat mazhab hukum Islam dan al-Ghazali dalam tasawuf sambil menekankan pentingnya tradisi lokal. Sebagai reaksi, Islam Nusantara adalah cara NU menanggapi keadaan saat ini dari masalah nasional dan global yang dihadapi NU dan umat Islam seperti fenomena radikalisme dan ekstremisme. Reaksi ini diambil untuk melindungi religiusitas anggota $\mathrm{NU}$ dari intervensi ajaran lain. Namun, aksi dan reaksi $\mathrm{NU}$ sering diungkapkan oleh NU seolah-olah merendahkan dan mengingkari pemikiran organisasi Muslim lainnya. Inilah kelemahan Islam Nusantara dan ide-ide lain yang sering dirumuskan dalam istilah biner. ${ }^{26}$

Debat semantik dan kritik publik tentang isu-isu Islam yang baru sangat dianjurkan sebagai bagian dari demokratisasi dan kebebasan berpikir di Indonesia. Namun, perdebatan dan kritik harus berorientasi pada objektivitas dengan pola pikir penyelesaian masalah. Tampaknya perdebatan dan kritik Islam Nusantara, sejak saat perumusannya pada tahun 2015, belum membahas masalah mendasar. Banyak penentang Islam Nusantara tidak mempermasalahkan substansi, isi, metode, epistemologi Islam Nusantara, tetapi lebih fokus pada semantik. Proliferasi media sosial, di samping itu, membuat perdebatan tentang Islam Nusantara semakin dangkal. Karakter media sosial yang cepat, reaksioner, dan instan melemahkan kemungkinan menjadi adil dalam berdebat Islam Nusantara. Hoax dan berita palsu yang didistribusikan melalui platform media sosial seperti Facebook, Twitter dan Instagram mengikis keadaan yang sebenarnya. Selain itu, para kritikus Islam Nusantara umumnya melanjutkan dari definisi mereka sendiri tentang konsep ini, bukan pada pemahaman yang mendalam dan hati-hati dan praktik pengecekan-dan-pemeriksaan ulang demi klarifikasi fakta dan mencari kebenaran. Tidak aneh jika pendekatan ini membawa kritik ke penilaian yang adil dan tidak adil terhadap konsep Islam Nusantara yang benar. ${ }^{27}$ Padahal di dalamnya jika dikaji secara intelektualitas maka islam Nusantara diposisikan sebagai salah satu pendekatan dalam mengkaji Islam yang akan melahirkan berbagai displin ilmu. Seperti fikih Nusantara, siyasah Nusantara, muamalah Nusantara, qanun Nusantara,

\footnotetext{
${ }^{26}$ Azra, "Kontestasi Pemikiran Islam Indonesia Kontemporer."

27"Tentang NU - Basis Pendukung," NU Online: Soeara Nahdlatoel Oelama, 2018, http://www.nu.or.id/about/basis+pendukung.
} 
perbankan Islam Nusantara, ekonomi Islam Nusantara, dan berbagai cabang ilmu Islam lain atas dasar sosioepisteme ke-Nusantara-an. Namun, kritik tersebut sebagian disebabkan oleh para pendukung Islam Nusantara sendiri yang tidak menjual ide dengan cukup baik dengan menyediakan tubuh yang kuat dari konsep-konsep yang mendukung Islam Nusantara sebagaimana telah ditemukan dalam teologi Islam. Karena itu, banyak pendukung Islam Nusantara terperangkap dalam perdebatan dan bereaksi secara dangkal terhadap masyarakat muslim yang kontra. Untuk menghasilkan debat yang lebih bermanfaat tentang Islam Nusantara, baik pendukung maupun penentang gagasan ini harus mengintensifkan dialog dan percakapan timbal balik berdasarkan ketulusan dan objektivitas. Perdebatan dan kritik berbasis bukti dan pengetahuan adalah strategi yang lebih disukai tentang Islam Nusantara yang sekaligus berfokus pada substantif yang bermakna. Para pendukung Islam Nusantara harus sadar bahwa ide-ide mereka tidak akan bebas dari kritik, kesalahpahaman dan bahkan ketidaksetujuan dari masyarakat Muslim Indonesia. Meskipun Islam Nusantara dipromosikan oleh organisasi Muslim terbesar di Indonesia, tidak ada jaminan bahwa ide ini dapat diterima oleh komunitas Muslim atau bahkan di antara anggota Nahdlatul Ulama. Seperti diketahui secara luas, bahkan di kalangan elit $\mathrm{NU}$, diskusi dan debat tentang Islam Nusantara tetap intens. NU Garis Lurus ( $N U$ Straight Path), misalnya, tidak setuju dengan konsep ini. Para pengikut almarhum Hasyim Muzadi, seorang pemimpin karismatik NU, lebih suka menggunakan "Islam Rahmatan lil 'Alamin" (Islam sebagai berkah universal untuk semua ciptaan Tuhan) daripada Islam Nusantara. Atas dasar ini, sangat penting untuk mempertimbangkan pentingnya saling pengertian dan menghormati keragaman ide tentang Islam Indonesia di antara komunitas Muslim. Para penentang Islam Nusantara juga harus memahami bahwa umat Islam memiliki hak untuk berpikir, menafsirkan dan mempraktikkan agama mereka yang dipandu oleh ijtihad (doktrin penalaran intelektual Islam dalam pemecahan masalah). Sebagai produk ijtihād, Islam Nusantara memiliki hak untuk dihormati. ${ }^{28}$ Namun, tantangan modern harus dihadapi oleh Islam Nusantara, karena tantangan abad ke-21 tidak sama dengan tantangan pada abad terakhir. Jika Islam Nusantara hanya didefinisikan dalam terang konsep Islam tradisional tentang 'Islam', itu tidak cukup untuk masalah abad ke-21 kita. Bagaimana umat Islam di Nusantara berurusan dengan Syiah dan Ahmadiyah, misalnya, yang

${ }^{28}$ Khabibi Muhammad Luthfi, "Islam Nusantara: Relasi Islam dan Budaya Lokal," Shahih: Journal of Islamicate Multidisciplinary 1, no. 1 (2016): 1-12, https://doi.org/10.22515/ shahih.v1i1.53. 
dianggap sebagai penyimpangan bahkan kafir, oleh beberapa Muslim? Ini adalah salah satu masalah utama kehidupan keagamaan Indonesia saat ini. Tidak diragukan lagi, penilaian penyimpangan atau perselingkuhan ini mengarah pada diskriminasi. Orang juga tidak dapat menyangkal bahwa mereka yang mendiskriminasi kaum Syiah, yang menyebabkan mereka melarikan diri dari desa mereka di Sampang Madura, Jawa Timur, adalah orang-orang NU. Dalam hal ini, jika Islam Nusantara tidak memiliki solusi yang diusulkan untuk masalah seperti itu dan tidak ada upaya untuk menangani rekonsiliasi dan mengakhiri ketidakadilan yang dialami oleh Syiah dan Ahmadiyah, Islam Nusantara hanyalah nama baru untuk konten lama, ${ }^{29}$ yang tidak memberikan landasan epistemologi Islam Nusantara yang bersifat positivistik dan "non-positivistik". 30

Terlepas dari pro dan kontra, Quraish Shihab melihat Islam Nusantara pada sisi "substansi", bukan bentuk. Apabila ada bentuk (budaya) yang secara substansi sesuai dengan Islam maka akan diterima, jika bertentangan akan ditolak dan direvisi. Inilah prinsip Islam dalam beradaptasi dengan budaya. Jadi Islam itu bisa bermacam macam akibat keragaman budaya setempat. Bahkan adat, kebiasaan dan budaya bisa menjadi salah satu sumber penetapan hukum Islam. Mustofa Bisri, meletakkan Islam Nusantara sebagai "sistem nilai" dan penerapannya dalam menanggapi masalah-masalah aktual dari waktu ke waktu. Mustofa Bisri cenderung melihat Islam Nusantara pada nilai-nilai yang selama ini dipraktekkan, diresapi, dan dijadikan prinsip warga $\mathrm{NU}$, seperti tasamuh (toleran), tawazun (seimbang/harmoni), tawassut (moderat), ta'addul (keadilan), dan 'amr ma'rüf nahi munkar. Sehingga Islam Nusantara ditempatkan secara aksiologis. ${ }^{31}$

\section{Self-Esteem dalam Deklarasi NU 1983}

Definisi self-esteem secara etimologi berasal dari kata Latin aestumare yang berarti "to estimate or to appraise" lebih jelasnya adalah menilai. Beberapa tokoh mendifinisikan mengenai self-esteem diantaranya Rosenberg mengartikan self-esteem adalah suatu sikap positif atau negatif terhadap obyek khusus, yaitu penilaian diri (self). Lebih lanjut ia menyatakan self-esteem secara jelas dapat diartikan sebagai komponen evaluasi terhadap kepribadian diri sendiri, yang melibatkan affect (perasaan), attitude (sikap), serta appraisal (penilaian) atau personal judgment. Steinberg memberikan gambaran self-esteem adalah se-

${ }^{29}$ Luthfi.

${ }^{30}$ Luthfi.

${ }^{31}$ Luthfi.

JURNAL THEOLOGIA — Volume 29, Nomor 2, Desember 2018 
berapa positif atau negatif individu menilai dirinya. Coopersmith mendefinisikan self-esteem sebagai penilaian dan penghargaan diri yang dilakukan individu terhadap dirinya sendiri. Menurut Branden definisi self-esteem adalah: "It is an intergrated sum of selfconfidence and self-respect. It is the disposition to experience one self as competent to cope with the basic challenges of life and as worthy of happiness." Self-esteem adalah penjumlahan terintegrasi dari self-confidence dan self-respect. Self-esteem merupakan disposisi individu untuk mengalami dirinya sebagai orang yang kompeten dalam menghadapi tantangan-tantangan dasar kehidupan dan merasa layak untuk bahagia. ${ }^{32}$

Dari pengertian tersebut dapat dilihat bahwa pengembangan diri seseorang dipengaruhi oleh self-esteem dalam pengorganisian mental pribadi dan control balanced identitas diri. Self-esteem akan memberikan solusi-solusi prediksi keputusan individu dalam menghadapi persoalan dirinya. Prediksi ini kan mempengaruhi motivasi serta keselarasan sikap dalam pikiran dan tindakan individu. Tindakan ini akan mengkofirmasi dan memperkuat sistem belief individu dengan segala pertimbangan-pertimbangan yang matang. ${ }^{33}$ Informasi dan lingkungan memberikan sebuah konsep pandangan baru individu dalam mengkontruksi motivasi diri dan kemampuan interaksi sosial positif dalam proses internalisasi diri. Proses internalisasi diri tersebut dalam pembentukan pertimbangan-pertimbangan diri sebagai sosial self dipengaruhi tiga aspek yang saling berhubungan (interrelated), pertama self-concept merupakan deskripsi dari apa yang orang persepsikan terhadap dirinya sendiri. Kedua selfesteem merupakan komponen afektif dari self, yang ketiga self-presentation, yang merupakan manifestasi tingkah laku dari self. Sosial self yang akan dipaparkan dalam artikel ini adalah penjelasan mendalam mengenai self-esteem yang terkandung dalam teks deklarasi NU tahun 1983.34

Self-esteem memiliki dua komponen interrelated bersifat erat, artinya satu komponen dengan komponen lainnya harus saling melengkapi. Pertama selfefficacy, yaitu keyakinan yang terbentuk atas dasar kemampuan mental individu, kemampuan berpikir, kemampuan menilai, memilih dan memutuskan, yakin dengan kemampuannya memahami realita dan fakta yang berkaitan dengan

\footnotetext{
${ }^{32}$ Nathaniel Branden, The Six Pillars of Self-Esteem (USA: Bantam, 1994), 93.

${ }^{33}$ Harold H. Kelley, "Attribution Theory in Social Psychology," Nebraska Symposium on Motivation 15 (1967): 192-238, https://psycnet.apa.org/record/1968-13540-001.

${ }^{34}$ Andrew Gray, Indigenous Rights and Development: Self-Determination in an Amazonian Community (Oxford, New York: Berghahn Books, 1997), 167.
} 
kebutuhan dan minatnya; cognitive self-reliance. Self-efficacy ini berarti individu yakin kemampuannya untuk mempelajari apa yang dibutuhkan dan mengerjakan apa yang dibutuhkan untuk mencapai tujuan individu tersebut. Pandangan ini berasumsi agama adalah sebuah kebutuhan dalam penyelesaian masalah self. Selfefficacy pun merupakan pengakuan individu dapat berpikir, mengetahui, dan memperbaiki kesalahan. Dengan kata lain individu tersebut percaya pada proses mental dan kemampuannya. Branden menyebutkan bahwa apabila seseorang mengalami defisiensi dalam self-efficacy sangatlah berbahaya, karena individu ini akan terikat pada yang diketahui dan akan mengalami kesulitan dalam beradaptasi pada tuntutan atau situasi yang baru. ${ }^{35}$ Kedua self-respect, yaitu keyakinan akan nilai-nilai diri; sikap positif yang mengarah pada rasa layak untuk hidup dan merasa bahagia; merasa nyaman dalam mengeluarkan pikiran-pikiran, keinginan-keinginan, dan kebutuhan dengan baik; merasa bahwa kebahagiaan merupakan hak asasi bagi dirinya. Individu yang memiliki self-respect akan merasakan bahwa hidupnya bermakna, memiliki keyakinan bahwa kehidupan dan keberadaannya dapat membantu orang lain, merasa bahwa dirinya adalah individu yang baik, berguna, layak dihormati, dan layak memperjuangkan hak yang dimiliki untuk mencapai kesuksesan dan pemenuhan dirinya. ${ }^{36}$

Islam memandang ada hubungan erat antara negara dan self-esteem Muslim. Sebab itulah kemunculan paham baru yang keluar dari konteks kenegaraan di anggap hal yang tabu. Zona negara dan lingkup Islam sama-sama mengilhami kemanusian. Islam memandang kemanusiaan dalam bentuk ibadah sedangkan negara memandang kemanusiaan ke dalam bentuk perjuangan. Tentu posisi ideologi haruslah sejajar dengan menyeimbangkan dua kepentingan tersebut. ${ }^{37}$

Ideologi Pancasila yang telah disebutkan dalam sumber sejarah NU 1983 menggambarkan sebuah pemahaman dan penekanan khusus agar Muslim Indonesia mengemban misi kemanusiaan, agar tidak terpecah belah, bebas intervensi, dan tidak bermunculan disintegrasi baru dalam kedok religius center seperti pembertontakan DI/TII dan gerakan-gerakan Islam lain yang bertentangan dengan ideologi bangsa. ${ }^{38}$

${ }^{35}$ Branden, The Six Pillars of Self-Esteem.

${ }^{36} \mathrm{Gray}$, Indigenous Rights and Development: Self-Determination in an Amazonian Community.

${ }^{37}$ Saiful Mustofa, "Meneguhkan Islam Nusantara untuk Islam Berkemajuan: Melacak Akar Epistemologis dan Historis Islam (di) Nusantara," Epistemé: Jurnal Pengembangan Ilmu Keislaman 10, no. 2 (2015): 405-34, https://doi.org/10.21274/epis.2015.10.2.405-434.

${ }^{38}$ Stéphane A. Dudoignon, Hisao Komatsu, dan Yasushi Kosugi, Intellectuals in the Modern Islamic World: Transmission, Transformation and Communication (London: Routledge: New Horizons in Islamic Studies, 2009). 
Self-esteem manusia Islam Indonesia diharapkan mampu menerima pemahaman ideologi bangsa sebagai kritik ibadah dan kritik intelektual yang terarah pada misi kemanusiaan. Hal ini disoroti sebab intelektual Islam radikal memandang Pancasila sebagai asumsi bukan dari kaidah ketuhanan. Mereka memandang butir-butir ideologi Pancasila merupakan karya manusia yang tidak patut dijadikan sumber segala sumber hukum di Indonesia dan mengabaikan nilai kemanusiaan yang terkandung, sehingga mengakibatkan diskursus baru menentang keberadaan Pancasila sebagai ideologi bangsa serta menggatikan syariat Islam dengan sistem khilafah sebagai antitesa dari diiskursus yang baru. ${ }^{39}$ Justru ini akan berdampak negatif dalam kehidupan masyarakat plural Indonesia. Kelemahan self-esteem Muslim Indonesia terbukti pula dengan asumsi partai Islam di Indonesia yang tidak menemukan suara mayoritas dalam berdemokrasi, beberapa persentase kegagalan partai Islam dalam pemilu mencerminkan kepercayaan masyarakat Indonesia yang rendah terhadap loyalitas partai Islam. Tentu hal ini menjadi pertanyaan besar di dalam masyarakat Indonesia yang mayoritas masyarakat Islam.

Analisis ini menunjukkan bahwa self-esteem Muslim Indonesia sangatlah menurun. Salah satu penyebabnya adalah maraknya paham baru ideologi alternatif khilifah di Indonesia. Salah satu bukti adalah konsepsi politik organisasi Hizbut Tahrir Indonesia. Oleh sebab itu sumber teks Deklarasi NU 1983 ketika dipandang sebagai warisan sejarah adalah kunci dalam peningkatan self-esteem individu untuk kembali memandang Islam sebagai visi nasional dan mengemban amanat kenegaraan yang tidak keluar dari jati diri Individu Muslim Indonesia. Adapun penjelasan butir-butir deklarasi NU 1983 sebagai berikut:

1) Pancasila sebagai dasar dan falsafah negara Republik Indonesia bukanlah agama, tidak dapat menggantikan agama dan tidak dapat dipergunakan untuk menggantikan kedudukan agama.

Self-esteem yang didapat dari teks ini bahwa Muslim Indonesia harus paham ketika membentuk jiwa negarawan haruslah memposisikan dirinya sebagai warga negara Indonesia, artinya amanat nasional Pancasila adalah bagian dari perjuangan Islam, bukan perjuangan Islam bagian dari amanat nasional. NU memandang bahwa Islam bersifat universal sedangkan kenegaraan dalam konsep haruslah mengikuti kultur bangsa itu sendiri. Indonesia merupakkan bangsa pluralis oleh sebab itu ideologi yang digali merupakan

${ }^{39}$ Khoirurrijal, “Islam Nusantara sebagai Counter Hegemoni Melawan Radikalisme Agama.” 
konvensi bersama demi terciptannya kesejahteraan sosial dan bukan khilafah yang terporos hanya Islam saja. Lebih jelasnya kepentingan negara adalah kepentingan Islam dalam konteks Pancasila. ${ }^{40}$ Negara Indonesia bukan negara Islam akan tetapi negara yang dihuni mayortitas Islam, oleh sebab itu Pancasila dalam sumber tertulis ini tidak dapat menggantikan agama dan kedudukannya. Sehingga misi Islam secara nasional adalah menjalankan Pancasila dengan cara Islam dalam kehidupan berbangsa dan bernegara sesuai dengan kaidah kehidupan bersyariat. Artinya ketika berpolitik, bersosial dan berekonomi harus kembali ke amanat Pancasila demi terciptanya kesejahteraan bangsa.

Kehadiran ideologi alternatif yang mencampuradukan kepentingan negara dengan kepentingan Islam, menjadikan sudut pandang mereka berpolitik, bersosial dan berekonomi dengan cara aturan Islam, bukan kembali kepada amanat Pancasila. Dampaknya Pancasila sebagai pakem nasional menjadi terabaikan. Hal ini diakibatkan adanya diskursus baru mengenai Pancasila dan keyakinan terhadap kebenaran normatif yang mereka anggap misi Islam bukan misi nasional. Disamping itu, ini memunculkan disintegrasi baru dalam ranah intelektual karena proses misi tersebut sebagian telah ter-intervensi oleh paham radikal. ${ }^{41}$ Pandangan ini mengesampingkan kepentingan minoritas dalam ranah hak demokrasi dan hak bernegara. Sehingga proses pemurnian Islam secara ideologi dan khalifah menghadirkan embrio baru yang diluar sistem mereka, sehingga secara tidak sadar ter-radikalisasi intelektual ke-Islamannya. Misinya memaksakan Islam secara ideologi dan konsep jihad dengan orientasi musuh yang mereka labelkan terhadap penguasa yang zalim dan rezim la'natullāh. ${ }^{42}$ Sedangkan masalah baru pandangan radikalisme ini bukan bagian dari konsep khilafah yang berkembang di Indonesia. Kemudian proses perjuangan arti jihad para radikalis bukan konsep Islam khilafah Indonesia. Secara tidak langsung citra Islam menjadi buruk dan kepercayaan masyarakat terhadap Islam menurun bahkan di-era kontemporer menunjukan adanya Islamphobia sebagai dampak dari proses radikalisme tersebut. ${ }^{43}$

40Musthofa Musthofa, "Pendidikan Islam Perspektif Humanisme-Pancasila," Jurnal Tarbiyah 24, no. 1 (2017): 157-80, https://doi.org/10.30829/TAR.V24I1.129.

${ }^{41}$ Wiarta Hendrisman Sianturi, "Pencegahan dan Penanggulangan Terorisme untuk Menjaga Keutuhan NKRI," (2011), 8-16.

42Zulkifli Haji Mohd Yusoff dan Fikri Mahmud, "Gerakan Teroris dalam Masyarakat Islam: Analisis terhadap Gerakan Jemaah Islamiyah (II)," Jurnal Usuluddin 21 (2005): 39-62.

${ }^{43} \mathrm{Amir}$ Saeed, "Media, Racism and Islamophobia: The Representation of Islam and Muslims in the Media," Sociology Compass 1, no. 2 (2007): 443-62, https://doi.org/10.1111/J.17519020.2007.00039.X. 
2) Sila Ketuhanan yang Mahaesa sebagai dasar negara Republik Indonesia menurut pasal 29 ayat (1) Undang-Undang Dasar 1945, yang menjiwai silasila yang lain, mencerminkan tauhid menurut pengertian keimanan dalam Islam.

Self-esteem dalam konteks hal ini memberikan sebuah dogma positif dari efect agama. Teks deklarasi poin kedua ini memberikan sebuah sumbangsih self concept dalam aktifitas individu untuk setiap melibatkan konsep ketuhanan dalam implementasi nilai-nilai Pancasila. Sebab banyak sekali penyelewengan konsep ketuhanan demi tujuan lainnya. Terbukti tentang keberadaan teroris di Indonesia merupakan bentuk penyelewengan konsep ketuhanan melalui misi jihad. ${ }^{44}$ Oleh sebab itu demi terbentuknya self-esteem konsep ketuhanan haruslah menjadi tujuan pertama dalam pembenaran segala konflik. Sebab keimanan dan tauhid dalam skala makro madzhab yang menyebar tidak mengenal dehumanisasi. Proses kristalisasi dogma Islam Nusantara tersebut memberikan pandangan bahwa self-esteem Muslim Indonesia haruslah memiliki kiblat dan mengesakan Allah serta menjadi orientasi implementasi ayat-ayat Pancasila lainnya yang merupakan bagian dari syariat agama. 45

3) Bagi Nahdlatul Ulama', Islam adalah akidah dan syari'ah, meliputi aspek hubungan manusia dengan Allah dan hubungan antar manusia.

Self-esteem terilhami dari konvensi tersebut adalah nilai humanisme. Islam ditegakkan di atas dasar kemanusiaan yang diajarkan al-Qur'an. Konsepsi Islam mengajarkan pada umatnya, bahwa Allah yang Maha Pengasih dan Maha Penyayang tidaklah menciptakan manusia dengan sia-sia. ${ }^{46}$ Dia telah mengaruniakan panca indera, akal dan fikiran serta menjadikan manusia dalam bentuk yang sebaik-baiknya, sempurna lahir dan batin. Humanisme dalam ajaran Islam tidaklah bersifat ekstrim seperti kedua pandangan di atas. Humanisme tidak mendewakan manusia dan juga tidak merendahkannya, Islam menempatkan manusia pada proporsi sebenarnya. ${ }^{47}$ Manusia merupakan

\footnotetext{
${ }^{44}$ Yusoff dan Mahmud, "Gerakan Teroris dalam Masyarakat Islam: Analisis terhadap Gerakan Jemaah Islamiyah (JI)."

${ }^{45}$ Mohamad Guntur Romli dan Tim Ciputat School, Islam Kita Islam Nusantara: Lima Nilai Dasar Islam Nusantara, Kata Pengantar oleh Denny J.A. (Tangerang: Ciputat School, 2016).

${ }^{46}$ Saifullah Idris dan Tabrani ZA, "Realitas Konsep Pendidikan Humanisme dalam Konteks Pendidikan Islam,” Jurnal Edukasi: Jurnal Bimbingan Konseling 3, no. 1 (2017): 96-113, https://doi.org/10.22373/je.v3i1.1420.

47Musthofa, "Pendidikan Islam Perspektif Humanisme-Pancasila."
} 
makhluk yang menerima amanah Tuhan agar dapat mengkelola alam semesta bagi kesejahteraan bersama. Dengan demikian manusia menjadi makhluk yang paling baik dan sempurna, apabila melaksanakan amanah tersebut. Sebaliknya individu Muslim akan menjadi makhluk yang hina apabila menghianati amanat itu dan berbuat kerusakan di muka bumi. ${ }^{48}$ Menurut pandangan Islam, mulia atau rendahnya menusia tidak terletak pada wujudnya semata sebagai makhluk Tuhan, akan tetapi terletak juga bagaimana individu Muslim dapat menjadikan dirinya bermanfaat bagi sesama makhluk. Apabila manusia beriman kepada Allah dan berbuat kebajikan sehingga mereka mampu berbuat banyak dalam mengelola alam maka ia menjadi makhluk terbaik. ${ }^{49}$

Sebaliknya apabila manusia ingkar dan berbuat kerusakan di muka bumi serta menghianati amanat yang luhur itu akan tercampak dalam kehinaan dan kenistaan. Amanat Allah yang diberikan kepada manusia adalah merupakan landasan yang kokoh baginya agar berkiprah dalam kehidupan ini sehingga menjadi makhluk yang terbaik. ${ }^{50}$ Manusia sajalah yang dapat menduduki derajat yang tinggi itu, karena tidak ada makhluk lain yang dapat melaksanakan amanat yang agung itu. Humanisme dalam Islam didasarkan pada prinsipprinsip yang nyata, fitri dan rasional. Melarang mendewakan manusia atau makhluk lain dan juga tidak merendahkan manusia sebagai makhluk yang hina dan berdosa. Humanisme dalam ajaran Islam didasarkan pada hubungan sesama umat manusia, baik hubungan sesama Muslim ataupun hubungan dengan umat lainnya. Humanisme Islam didasarkan pada saling mencintai, kasih sayang dan menjaga kebersamaan. ${ }^{51}$

“Sesungguhnya orang-orang mu'min adalah bersaudara karena itu damaikanlah antara kedua saudaramu dan bertaqwalah kepada Allah agar kamu mendapat rahmat." ${ }^{52}$

\footnotetext{
48Musthofa.

${ }^{49}$ Nur Said, "Pendidikan Toleransi Beragama untuk Humanisme Islam di Indonesia," Edukasia: Jurnal Penelitian Pendidikan Islam 12, no. 2 (2017): 409-34, https://doi.org/10.21043/ EDUKASIA.V12I2.2445.

50Zainul Arifin, "Nilai Pendidikan Humanis - Religius," An-Nuha: Jurnal Kajian Islam, Pendidikan, Budaya \& Sosial 1, no. 2 (2015): 169-96, http://ejournal.staimadiun.acid/indexphp/ annuha/article/view/7.

${ }^{51}$ Idris dan ZA, "Realitas Konsep Pendidikan Humanisme dalam Konteks Pendidikan Islam."

${ }^{52}$ QS. al-Hujurāt: 10.
} 
"Tidak ada kebaikan pada kebanyakan bisikan mereka, kecuali bisikan dari orang yang menyuruh manusia bersedekah, atau berbuat yang ma'ruf atau mengadakan perdamaian diantara manusia."53

Berpegang teguh pada agama Allah, tidak berselisih, tidak bercerai berai dan selalu menghindari permusuhan. "Dan berpegang teguhlah kepada tali (agama) Allah dan jangan bercerai berai." 54

"Janganlah kamu saling bermusuhan yang menyebabkan kamu menjadi lemah dan hilang kekuatanmu dan bersabarlah."55

Menjalin hubungan dengan umat lain yang tidak memusuhi umat Islam dengan jalan saling kenal mengenal, saling berbuat baik dan saling bersikap adil. "Wahai manusia sesungguhnya Kami menciptakanmu dari seorang laki-laki dan seorang perempuan serta menjadikan kamu berbagai bangsa dan suku agar kamu saling kenal mengenal."56

"Allah tiada melarang kamu untuk berbuat baik dan berlaku adil terhadap orang-orang yang tiada memerangimu karena agama dan tidak pula mengusir kamu dari negerimu. Sesungguhnya Allah menyukai orang-orang yang berlaku adil."57

"Tidak ada paksaan untuk memasuki agama; sesungguhnya telah jelas jalan yang benar dari jalan yang salah." 58

4) Penerimaan dan pengamalan Pancasila merupakan perwujudan dari upaya umat Islam Indonesia untuk menjalankan syari'at agamanya.

Self-esteem mencoba memasuki ranah nasional konvergensi agama ketika ormas NU mengemban tugas pengamalan Pancasila. Individu Muslim tentu akan terilhami sifat kebangsaan dan religius yang mampu membendung segala upaya-upaya yang melenceng dari tugas tersebut. Sehingga secara tidak langsung memberikan personal judgement terhadap individu dalam berbangsa dan bernegara. ${ }^{59}$ Sisi lain dari tujuan tersebut adalah menjalankan syariat agama

${ }^{53} \mathrm{QS}$. al-Nisā': 114.

${ }^{54}$ QS. Ali Imrān: 103.

${ }^{55}$ QS. al-Anfāl: 46.

${ }^{56}$ QS. al-Ḥujurāt: 13.

${ }^{57}$ QS. al-Mumtahanah: 8.

${ }^{58}$ QS. al-Baqarah: 256.

${ }^{59}$ Astuti, “Islam Nusantara: Sebuah Argumentasi Beragama dalam Bingkai Kultural.” 
yang terfokus terhadap bingkai kenegaraan. Anggapan akan konsep sajadah nasional bisa terwujud yaitu terbentuknya nasionalisme klasik yang teraksentuasi dari kepedulian akan negara sebagai (place) segala aktivitas syariat atau ibadah. Hubungan negara dan agama menjadi sebuah kesatuan dalam konteks revolusi Islam, sehingga tabiat self-esteem secara langsung dapat membentuk kesadaran agama dan ideologi..$^{60}$ Harapannya adalah menjadikan individu Muslim mengetahui bahwa negara dan agama sebagai control balanced dalam pengamalan Pancasila.

5) Sebagai konsekuensi dari sikap di atas, Nahdlatul Ulama' berkewajiban mengamankan pengertian yang benar tentang Pancasila dan pengamalannya yang murni dan konsekuen oleh semua pihak.

Definisi dan asumsi mengenai Pancasila dan korelasinya dengan agama menjadi tugas umat Islam. Tafsir lainnya yang bertentangan atau keluar dari konvensi maka dikonsekuensikan dengan tujuan bersama. Self-esteem dari keputusan ini adalah memberikan kemampuan akan jati diri individu Muslim untuk menjaga konsekuensi pengamanan pengertian Pancasila sebagai perwujudan dari etos agama dan etos ideologi. ${ }^{61}$

\section{Kesimpulan}

Konsep Islam Nusantara NU 2015 dalam ranah kebangsaan merupakan internalisasi dan implementasi nilai-nilai teks Deklarasi NU 1983. Konsep Islam Nusantara menjawab konflik intelektual Islam yang mengalami degradasi intelektual dalam perkembangan kontemporer serta mengalami radikalisasi secara sistemik di kehidupan sosial. Teks Deklarasi NU 1983 memberikan penguatan adanya hubungan Islam dan Pancasila sebagai self-esteem dalam menangani konflik tersebut, sehingga dapat menjadi pedoman bagi Muslim Indonesia. Konsep Islam Nusantara NU 2015 dan teks Deklarasi NU 1983 adalah self-esteem Muslim Indonesia dalam berbangsa dan bernegara.[]

\footnotetext{
${ }^{60}$ Arifin, "Nilai Pendidikan Humanis - Religius."

${ }^{61}$ Mujamil Qomar, "Islam Nusantara: Sebuah Alternatif Model Pemikiran, Pemahaman, dan Pengamalan Islam,” El-Harakah: Jurnal Budaya Islam 17, no. 2 (2015): 198, https://doi.org/ 10.18860/el.v17i2.3345.
} 


\section{DAFTAR PUSTAKA}

Abdullah, Anzar. "Gerakan Radikalisme dalam Islam: Perspektif Historis." Addin 10, no. 1 (2016): 1-28. https://doi.org/10.21043/addin.v10i1.1127.

___. "Nahdlatul Ulama and the Khittah Revitalization: A Futuristic Critical Reflection for the Largest Islamic Organization in Indonesia." Tawarikh: International Journal for Historical Studies 3, no. 1 (2011): 95-108. http://www.journals.mindamas.com/index.php/tawarikh/article/view/ $398 /$.

Arifin, Zainul. "Nilai Pendidikan Humanis - Religius." An-Nuha: Jurnal Kajian Islam, Pendidikan, Budaya \& Sosial 1, no. 2 (2015): 169-96. http://ejournal. staimadiun.ac.id/index.php/annuha/article/view/7.

Astuti, Hanum Jazimah Puji. "Islam Nusantara: Sebuah Argumentasi Beragama dalam Bingkai Kultural." Inject: Interdisciplinary Journal of Communication 2, no. 1 (2017): 27-51.https://doi.org/10.18326/inject.v2i1.27-51.

Azra, Azyumardi. "Islam in Southeast Asia: Tolerance and Radicalism." Dalam Miegunyah Public Lecture, 1-19. Melbourne: The University of Melbourne, 2005.

——_. "Kontestasi Pemikiran Islam Indonesia Kontemporer." Studia Islamika 23, no. 1 (2016): 175-84. https://doi.org/10.15408/sdi.v23i1.2905.

- - C. "Pluralism, Coexistence and Religious Harmony in Southeast Asia: Indonesian Experience in the 'Middle-path".' Dalam Contemporary Islam: Dynamic, not Static, diedit oleh Abdul Aziz Said, Mohammed Abu-Nimer, dan Meena Sharify-Funk, 227-41. London: Routledge, 2006.

Branden, Nathaniel. The Six Pillars of Self-Esteem. USA: Bantam, 1994.

Buckley, Peter. "The Psychohistory Review. VIII, 1979: A Note on the Adaptation of the Psychoanalytic Method to the Study of Historical Personalities: Psychoanalysts on Schreber. Carl Pletsch. Pp. 46-50." The Psychoanalytic Quarterly 51 (1982): 169-70. https://www.pep-web.org/document.php? id=paq.051.0169c.

CNN. Survei Alvara_Sebagian Milenial Setuju Khilafah (2018).

Dudoignon, Stéphane A., Hisao Komatsu, dan Yasushi Kosugi. Intellectuals in the Modern Islamic World: Transmission, Transformation and Communication. London: Routledge: New Horizons in Islamic Studies, 2009. 
Fadly, Muhammad Akhyar. "Gerakan Radikalisme Agama: Perspektif Ilmu Sosial." El-Hikam: Journal of Education and Religious Studies 9, no. 1 (2016): 87-104. http://ejournal.kopertais4.or.id/sasambo/index.php/elhikam/article/view $/ 1881 /$.

Fuad, Fokky. "Islam dan Ideologi Pancasila, Sebuah Dialektika." Lex Jurnalica (Journal of Law) 9, no. 3 (2012). https://ejurnal.esaunggul.acid/ index.php/Lex/article/view/346.

Ghazali, Abdul Moqsith. "Metodologi Islam Nusantara." Dalam Islam Nusantara: Dari Ushul Fiqh Hingga Paham Kebangsaan, diedit oleh Akhmad Sahal dan Munawir Azis, 106-16. Bandung: Mizan Pustaka, 2016.

Goncing, Nurlira. "Politik Nahdlatul Ulama dan Orde Baru." The Politics: Jurnal Magister Ilmu Politik Universitas Hasanuddin 1, no. 1 (2015): 61-74.

Gray, Andrew. Indigenous Rights and Development: Self-Determination in an Amazonian Community. Oxford, New York: Berghahn Books, 1997.

Hefner, R. W. The Politics of Multiculturalism: Pluralism and Citizenship in Malaysia, Singapore, and Indonesia. Hawai: University of Hawai'i Press, 2001.

Hendrisman Sianturi, Wiarta. "Pencegahan dan Penanggulangan Terorisme untuk Menjaga Keutuhan NKRI," 2011.

Idris, Saifullah, dan Tabrani ZA. "Realitas Konsep Pendidikan Humanisme dalam Konteks Pendidikan Islam." Jurnal Edukasi: Jurnal Bimbingan Konseling 3, no. 1 (2017): 96-113. https://doi.org/10.22373/je.v3i1.1420.

Kelley, Harold H. "Attribution Theory in Social Psychology." Nebraska Symposium on Motivation 15 (1967): 192-238. https://psycnet.apa.org/record/196813540-001.

Khoirurrijal. "Islam Nusantara sebagai Counter Hegemoni Melawan Radikalisme Agama." Akademika: Jurnal Pemikiran Islam 22, no. 1 (2017): 78-102. https://doi.org/10.32332/akademika.v22i1.616.

Luthfi, Khabibi Muhammad. "Islam Nusantara: Relasi Islam dan Budaya Lokal." Shahih: Journal of Islamicate Multidisciplinary 1, no. 1 (2016): 1-12. https://doi.org/10.22515/shahih.v1i1.53.

_—_. "Kontekstualisasi Filologi dalam Teks-Teks Islam Nusantara." Ibda: Jurnal Kajian Islam dan Budaya 14, no. 1 (2016): 114-28. https://doi.org/ 10.24090/IBDA.V14I1.523. 
Musthofa, Musthofa. "Pendidikan Islam Perspektif Humanisme-Pancasila." Jurnal Tarbiyah 24, no. 1 (2017): 157-80. https://doi.org/10.30829/ TAR.V24I1.129.

Mustofa, Saiful. "Meneguhkan Islam Nusantara untuk Islam Berkemajuan: Melacak Akar Epistemologis dan Historis Islam (di) Nusantara." Epistemé: Jurnal Pengembangan Ilmu Keislaman 10, no. 2 (2015): 405-34. https://doi.org/10.21274/epis.2015.10.2.405-434.

Naim, Ngainun. "Islam dan Pancasila: Rekonstruksi Pemikiran Nurcholish Madjid." Epistemé: Jurnal Pengembangan Ilmu Keislaman 10, no. 2 (2015): 435-56. https://doi.org/10.21274/epis.2015.10.2.435-456.

Nor Huda. Islam Nusantara: Sejarah Sosial Intelektual Islam di Indonesia. Yogyakarta: Ar-Ruzz Media, 2007.

Nurhisam, Luqman, dan Mualimul Huda. "Islam Nusantara: A Middle Way?" QIJIS: Qudus International Journal of Islamic Studies 4, no. 2 (2016): 152-66. https://doi.org/10.21043/qijis.v4i2.1763.

Panitia Muktamar PBNU, ed. Panduan Acara Muktamar ke-33. Jombang: PBNU, 2015.

Qomar, Mujamil. "Islam Nusantara: Sebuah Alternatif Model Pemikiran, Pemahaman, dan Pengamalan Islam." El-Harakah: Jurnal Budaya Islam 17, no. 2 (2015): 198. https://doi.org/10.18860/el.v17i2.3345.

Rabasa, Angel, Cheryl Benard, Lowell H. Schwartz, dan Peter Sickle. Building Moderate Muslim Networks. Santa Monica, CA: RAND Corporation, 2007. https://www.rand.org/content/dam/rand/pubs/monographs/2007/RA ND_MG574.pdf.

Romli, Mohamad Guntur, dan Tim Ciputat School. Islam Kita Islam Nusantara: Lima Nilai Dasar Islam Nusantara. Kata Pengantar Denny J.A. Tangerang: Ciputat School, 2016.

Saeed, Amir. "Media, Racism and Islamophobia: The Representation of Islam and Muslims in the Media." Sociology Compass 1, no. 2 (2007): 443-62. https://doi.org/10.1111/J.1751-9020.2007.00039.X.

Said, Nur. "Pendidikan Toleransi Beragama untuk Humanisme Islam di Indonesia." Edukasia: Jurnal Penelitian Pendidikan Islam 12, no. 2 (2017): 409-34. https://doi.org/10.21043/EDUKASIA.V12I2.2445. 
Susanto, Edi, dan Karimullah Karimullah. "Islam Nusantara: Islam Khas dan Akomodatif terhadap Budaya Lokal." Al-Ulum 16, no. 1 (2016): 56-80. https://doi.org/10.30603/au.v16i1.27.

“Tentang NU - Basis Pendukung." NU Online: Soeara Nahdlatoel Oelama, 2018. http://www.nu.or.id/about/basis+pendukung.

Yusoff, Zulkifli Haji Mohd, dan Fikri Mahmud. "Gerakan Teroris dalam Masyarakat Islam: Analisis terhadap Gerakan Jemaah Islamiyah (JI)." Jurnal Usuluddin 21 (2005): 39-62.

\section{Lampiran \\ Teks Deklarasi NU Tahun 1983}

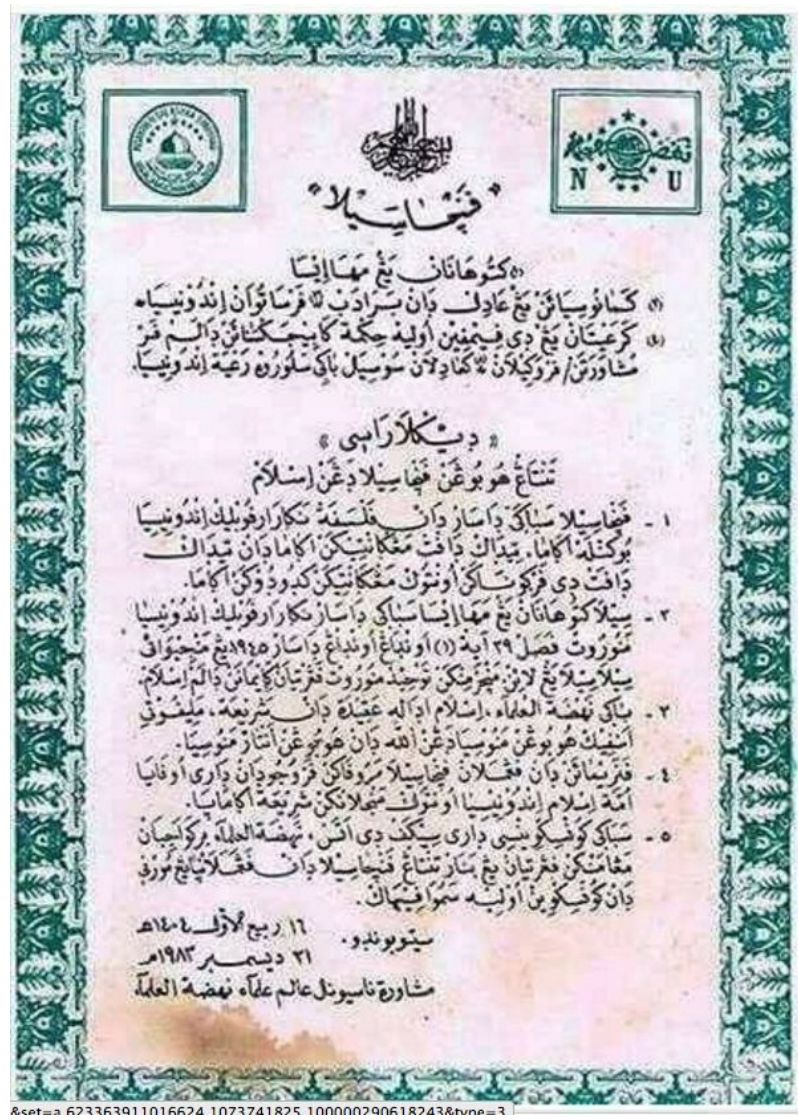

JURNAL THEOLOGIA - Volume 29, Nomor 2, Desember 2018 
Transliterasi Tulisan Arab Melayu (Arab Pegon)

\section{Deklarasi tentang Hubungan Pancasila dengan Islam}

1. Pancasila sebagai dasar dan falsafah negara Republik Indonesia bukanlah agama, tidak dapat menggantikan agama dan tidak dapat dipergunakan untuk menggantikan kedudukan agama.

2. Sila ketuhanan yang maha esa sebagai dasar negara Republik Indonesia menurut pasal 29 ayat (1) undang-undang dasar 1945, yang menjiwai silasila yang lain, mencerminkan tauhid menurut pengertian keimanan dalam Islam.

3. Bagi Nahdlatul Ulama', Islam adalah akidah dan syari'ah, meliputi aspek hubungan manusia dengan Allah dan hubungan antar manusia.

4. Penerimaan dan pengamalan Pancasila merupakan perwujudan dari upaya umat Islam Indonesia untuk menjalankan syari'at agamannya.

5. Sebagai konsekuensi dari sikap di atas, Nahdlatul Ulama' berkewajiban mengamankan pengertian yang benar tentang Pancasila dan pengamalannya yang murni dan konsekuen oleh semua pihak. 